\title{
Determinação da dissimilaridade genética entre acessos de Capsicum chinense com base em características de flores
}

\author{
Carla Sigales de Vasconcelos ${ }^{1}$, Rosa Lía Barbieri ${ }^{1}$, Raquel Silviana Neitzke ${ }^{2}$, Daniela Priori ${ }^{3}$, \\ Sintia Zitzke Fischer ${ }^{4}$, Claudete Clarice Mistura ${ }^{5}$
}

\section{RESUMO}

As pimentas do gênero Capsicum apresentam grande importância para o mercado de condimentos e para o uso ornamental no Brasil. A estimativa da diversidade genética é importante na escolha de progenitores de programa de melhoramento genético. Este trabalho teve por objetivo verificar a eficiência de descritores multicategóricos de flores para estimar a dissimilaridade genética entre acessos de Capsicum chinense, do Banco Ativo de Germoplasma Capsicum, da Embrapa Clima Temperado. O experimento foi realizado no período de agosto de 2009 a março de 2010, no campo experimental da Embrapa Clima Temperado, em blocos ao acaso, utilizando-se 22 acessos, com dez plantas por parcela. Para a caracterização morfológica das flores, foram avaliadas cinco flores de cada planta, de dez plantas por acesso. Foram utilizados 15 descritores, sendo cinco quantitativos e dez qualitativos multicategóricos. Foram realizadas análises de comparação de médias, utilizando-se agrupamento pelos métodos UPGMA e de Tocher, para os dados quantitativos, e agrupamento pelo método de Tocher, para os dados qualitativos. Os acessos estudados apresentam ampla diversidade genética em relação a descritores de flores, existindo grande variabilidade entre os acessos avaliados, o que recomenda seu uso em programas de melhoramento genético. O uso de descritores multicategóricos de flores é eficiente para estimar a dissimilaridade genética entre acessos de Capsicum chinense.

Palavras-chave: pimentas, Solanaceae, recursos genéticos, banco ativo de germoplasma.

\section{ABSTRACT}

\section{Genetic dissimilarity among Capsicum chinense accessions based on flower characteristics}

Capsicum peppers are extremely important in Brazil for the spice market and as ornamental. The estimation of genetic diversity is important for the choice of parents in a breeding program. This study aimed to evaluate the efficiency of multicategoric descriptors for flowers to estimate the genetic dissimilarity among Capsicum chinense accessions from the Capsicum Active Germplasm Bank of Embrapa Temperate Agriculture The experiment was conducted from October 2009 to March 2010 in the experimental field of Embrapa Temperate Agriculture, with 22 accessions evaluated in randomized blocks and ten plants per plot. Five flowers of each plant, ten plants per access were used for the morphological characterization of the flowers. Five quantitative and ten qualitative multicategoric descriptors were used, making a total of 15. Mean comparison tests were carried out, and the clustering methods UPGMA and Tocher

\footnotetext{
Recebido para publicação em 27/10/2010 e aprovado em 09/04/2012.

'Bióloga. Embrapa Clima Temperado, Caixa Postal 403, 96010-971, Pelotas, Rio Grande do Sul, Brasil. carla_sigales@hotmail.com (autora para correspondência); lia.barbieri@gmail.com

${ }^{2}$ Engenheira-Agrônoma, Mestre. Doutoranda da Universidade Federal de Pelotas (UFPel-FAEM), Caixa Postal 354, 96001-970, Pelotas, Rio Grande do Sul, Brasil. raquelsilviana@gmail.com

${ }^{3}$ Bióloga. Mestranda da Universidade Federal de Pelotas (UFPel-FAEM), Caixa Postal 354, 96001-970, Pelotas, Rio Grande do Sul, Brasil. dani_priori@yahoo.com.br ${ }^{4}$ Engenheira-Agrônoma, Mestre. Doutoranda da Universidade Federal de Pelotas (UFPel-FAEM), Caixa Postal 354, 96001-970, Pelotas, Rio Grande do Sul, Brasil. sintiafischer@gmail.com

${ }^{5}$ Engenheira-Agrônoma, Mestre. Doutoranda da Universidade Federal de Pelotas (UFPel-FAEM), Caixa Postal 354, 96001-970, Pelotas, Rio Grande do Sul, Brasil. c.mistura@hotmail.com
} 
were used for quantitative data, and the Tocher method for qualitative data. The accessions showed wide genetic diversity in relation to descriptors of flowers, with great variability among accessions, which recommends its use in breeding programs. The use of multicategoric descriptors for flowers is efficient to estimate the genetic dissimilarity among accessions of Capsicum chinense.

Key words: peppers, Solanaceae, genetic resources and germplasm active bank.

\section{INTRODUÇÃO}

As pimentas do gênero Capsicum pertencem à família Solanaceae (Prince et al., 1993) e abrangem espécies domesticadas, semidomesticadas e silvestres, originadas das Américas Central e do Sul. As espécies cultivadas C. annuum, C. baccatum, C. chinense, $C$. frutescens e C. pubescens têm grande importância agronômica (Pickersgill, 1991; Belletti et al., 1998 \& Paran et al., 1998).

As pimentas do gênero Capsicum são amplamente cultivadas no mundo, sendo utilizadas como matéria-prima para as indústrias alimentícia, farmacêutica e cosmética (Yamamoto et al., 2007). O cultivo de pimentas no Brasil é de grande importância, tanto pelas características de rentabilidade, principalmente quando o produtor agrega valor ao produto, quanto pela importância social, por empregar elevada mão de obra (Rufino \& Penteado, 2006).

Capsicum chinense merece destaque na agricultura brasileira, por ser, geralmente, cultivada em pequenas propriedades, nas quais se utiliza mão de obra familiar. Seus frutos são muito utilizados como condimentos e especiarias. A espécie apresenta propriedades farmacêuticas, tais como anestésica e anti-inflamatória. Porém, há carência de variedades melhoradas com características de cor, aroma e pungência de fruto, que atendam às necessidades da indústria, dificultando o desenvolvimento de um mercado mais organizado (Bosland \& Votava, 2000).

As diferentes espécies e variedades de pimentas podem ser discriminadas por características morfológicas dos frutos e, principalmente, das flores (Moreira et al., 2006). A posição da flor e do pedicelo, a presença ou ausência de manchas nos lobos das pétalas, a margem do cálice e o número de flores por entrenó têm importância taxonômica na discriminação das espécies (Carvalho \& Bianchetti, 2004). Estes e outros caracteres das flores poderiam ser utilizados como marcadores morfológicos para determinar a divergência genética entre acessos de bancos de germoplasma, com a vantagem de poderem ser avaliados no início do ciclo reprodutivo das plantas.

Diante deste contexto, este trabalho teve como objetivo verificar a eficiência de descritores multicategóricos de flores para estimar a dissimilaridade genética entre aces- sos de C.chinense, do Banco Ativo de Germoplasma Capsicum, da Embrapa Clima Temperado.

\section{MATERIAL E MÉTODOS}

O experimento foi conduzido no campo experimental da Embrapa Clima Temperado, no município de Pelotas, Rio Grande do Sul (coordenadas geográficas: $31^{\circ} 40^{\prime} 47^{\prime \prime} S$ e 52 $26^{\prime} 24^{\prime \prime} \mathrm{W} ; 60 \mathrm{~m}$ de altitude).

Foram caracterizados 22 acessos de pimentas Capsicum chinense, que fazem parte do acervo do Banco Ativo de Germoplasma de Capsicum, da Embrapa Clima Temperado (Tabela 1).

O experimento foi conduzido no período de 03 de agosto de 2009 a 30 de março de 2010. Após 45 dias, as plântulas foram transplantadas para o campo. Foi utilizado o sistema de irrigação por gotejamento e feita a fertirrigação, de

Tabela 1. Acessos de pimentas Capsicum chinense que fazem parte do acervo do Banco Ativo de Germoplasma de Capsicum da Embrapa Clima Temperado

\begin{tabular}{ll}
\hline Acessos & Local \\
\hline P37 & Palmas, TO \\
P41 & Pedro Afonso, TO \\
P42 & Pedro Afonso, TO \\
P43 & Pedro Afonso, TO \\
P65 & Belém, PA \\
P66 & Belém, PA \\
P78 & Canoinhas, SC \\
P135 & Vassouras, RJ \\
P142 & Vassouras, RJ \\
P157 & Rio de Janeiro, RJ \\
P165 & Paraná \\
P166 & Pelotas, RS \\
P181 & Brasília, DF \\
P182 & Brasília, DF \\
P184 & Belém, PA \\
P190 & Porto Seguro, BA \\
P191 & Porto Seguro, BA \\
P192 & Porto Seguro, BA \\
P194 & Belém, PA \\
P196 & Belém, PA \\
P231 & Rio de Janeiro, RJ \\
P233 & Rio de Janeiro, RJ \\
\hline
\end{tabular}


acordo com a necessidade da cultura. Foram cultivadas dez plantas por acesso, com espaçamento de $0,6 \mathrm{~m}$ entre plantas e 1,20 m entre linhas.

Para a caracterização morfológica das flores, foram avaliadas cinco flores por planta, em dez plantas de cada acesso. Foram utilizados 15 descritores, sendo cinco quantitativos e dez qualitativos multicategóricos. Os descritores quantitativos avaliados foram número de pétalas, diâmetro da flor, comprimento do estigma, comprimento do pecíolo e comprimento da antera, com o auxílio de um paquímetro digital. Para os descritores qualitativos de flor, foi utilizada a listagem recomendada para Capsicum pelo International Plant Genetic Resources Institute (IPGRI, AVRDC, CATIE, 1995):

01. número de flores por axila: (1) uma; (2) duas; (3) três ou mais; (4) muitas com entrenó curto; (5) uma e duas; (6) uma, duas e três; (7) duas e três; (8) duas, três e quatro.

02. posição da flor: (3) pendente; (5) intermediária; (7) ereta; (9) todas; (11) intermediária e ereta; (13) pendente e intermediária.

03. cor da corola: (1) branco; (2) amarelo claro; (3) amarelo; (4) amarelo esverdeado; (5) violeta com base branca; (6) branco com base violeta; (7) branco com margem violeta; (8) violeta; (9) branco esverdeado; (10) branco com mancha púrpura; (11) branco esverdeado com mancha púrpura.

04. cor da mancha da corola: (1) branco; (2) amarelo; (3) amarelo esverdeado; (4) verde; (5) violeta; (6) sem mancha.

05. forma da corola: (1) rotada; (2) campanulada; (3) intermediária.

06. cor da antera: (1) branco; (2) amarelo; (3) azul pálido; (4) azul; (5) violeta; (6) amarelo com mancha azul claro.

07. cor do filamento: (1) branco; (2) amarelo; (3) verde; (4) azul; (5) violeta claro; (6) violeta; (7) azul violeta.

08. posição do estigma: (3) inserto; (5) mesmo nível; (7) excerto); (9) mesmo nível e excerto; (11) inserto e mesmo nível; (13) inserto e excerto.

09. pigmento do cálice: (0) ausente; (1) presente.

10. margem do cálice: (1) inteiro; (2) intermediário; (3) dentado.

Com base nas médias dos caracteres morfológicos, foi estimada a distância euclidiana dos acessos. Para estimar a dissimilaridade dos acessos, foi realizada análise multivariada (Cruz \& Regazzi, 1997), por meio do método de agrupamento de Tocher (Rao, 1952), com base nas distâncias generalizadas de Mahalanobis, utilizando-se o programa computacional GENES (Cruz, 2006). Com base na matriz de distância genética gerada, foi construído um dendrograma pelo método de agrupamento da distância média (UPGMA - Unweighted Pair-Group Method of Arithmetic Averages). Para a estimativa do ajuste entre a matriz de dissimilaridade e o dendrograma gerado, foi calculado o coeficiente de correlação cofenética (r) (Sokal \& Rohlf, 1962), utilizando-se o programa computacional NTSYS-pc (versão 2.01; Rohlf, 2001).

\section{RESULTADOS E DISCUSSÃO}

Os descritores qualitativos cor da mancha da corola e pigmento do cálice foram considerados monomórficos e desconsiderados na análise de dissimilaridade. Nenhum acesso avaliado apresentou a presença de mancha na corola, sendo esta uma característica de Capsicum chinense. O pigmento do cálice foi ausente para todos os acessos avaliados. Desta forma, foram utilizados 13 descritores, dos 15 iniciais, na análise da divergência genética, sendo oito qualitativos e cinco quantitativos.

O método de agrupamento de Tocher foi aplicado para os 22 acessos de Capsicum e possibilitou a formação de três grupos, para as variáveis multicategóricas qualitativas, e de 10 grupos, para as variáveis quantitativas.

$\mathrm{Na}$ Tabela 2, podem ser visualizados os três grupos distintos, formados a partir da análise dos dados qualitativos. Este método leva ao estabelecimento de grupos, de forma que exista homogeneidade dentro do grupo, e, heterogeneidade entre grupos. Além disso, é uma técnica de otimização que agrupa os indivíduos, mantendo o critério de que as distâncias intragrupos sejam sempre menores do que as intergrupos (Cruz \& Regazzi,1997). Desta maneira, a formação destes grupos representa uma importante informação na seleção de genitores dentro dos programas de melhoramento, pois as novas populações a serem formadas devem ser baseadas na amplitude de suas distâncias e na potencialidade dos genitores.

O G1, formado pelas variáveis qualitativas, apresentou homogeneidade para a característica margem do cálice, sendo esta intermediária. Para o descritor posição do estigma, dos 20 acessos avaliados, apenas três apresentaram o mesmo nível do estigma com relação à antera. Os outros 17 acessos apresentaram a posição do estigma

Tabela 2. Grupos de similaridade genética entre acessos de Capsicum chinense, formados pela análise das variáveis multicategóricas qualitativas, estabelecidos pelo método de Tocher, a partir da distância generalizada de Mahalanobis

\begin{tabular}{ll}
\hline Grupo & Acessos \\
\hline \multirow{3}{*}{ G1 } & P166, P191, P192, P65, P231, P194, P37, P182, \\
& P66, P142, P181, P184, P190, P42, P233, P157, \\
G2 & P165, P135, P196, P78 \\
G3 & P41 \\
\hline
\end{tabular}

Rev. Ceres, Viçosa, v. 59, n.4, p. 493-498, jul/ago, 2012 
excerto, estigma acima da antera, o que confere com os dados encontrados por Luz (2007) para C. chinense. Quanto à posição da flor, foram apresentadas as posições pendente, intermediária e ereta, sendo uma característica heterogênea no grupo. A cor da corola variou de branco esverdeado, amarelo claro a amarelo esverdeado. Quanto ao número de flores por axila, variou entre uma, duas ou três. A forma da corola foi outra característica bastante heterogênea no grupo, com todas as opções, intermediária (13 acessos), campanulada (5 acessos) e rotada (1 acesso). A cor da antera também foi heterogênea: 13 acessos apresentaram a cor violeta; quatro, azul;um acesso, amarelo, e um, azul pálido.

O G2 foi formado por um único acesso, que apresentou uma, duas e três flores por axila; posição da flor, pendente; cor da corola, amarela clara; forma da corola, intermediária; cor da antera, azul; cor do filamento, branco; posição do estigma, excerto, sendo o único entre todos os acessos avaliados neste trabalho a apresentar cálice dentado.

O G3 também foi formado por um único acesso, que apresentou uma flor por axila; posição da flor, pendente; cor da corola, branca; forma da corola, campanulada; cor da antera, azul; cor do filamento, violeta; posição do estigma, no mesmo nível da antera e margem do cálice intermediário.

Para os dados quantitativos, pelo método de Tocher (Tabela 3), foram formados dez grupos: o G1, com 10 acessos ; o G2, com dois acessos; o G3, com dois acessos; G4,com dois acessos; G5, G6, G7, G8, G9 e G10, com um acesso, cada. Pelo método do UPGMA, foram formados quatro grupos, sendo agrupados 16 acessos no G1; três acessos no G2; um acesso, no G3 e dois acessos, no G4.

Para a característica número de pétalas, o grupo 1 apresentou homogeneidade para o número de pétalas, cinco, para todos os acessos. O diâmetro da flor variou de 6 a 9

Tabela 3. Grupos de similaridade genética entre acessos de Capsicum chinense, formados pela análise dos dados quantitativos, usando o método de Tocher, a partir da distância generalizada de Mahalanobis

\begin{tabular}{ll}
\hline Grupo & Acessos \\
\hline G1 & P42, P233, P184, P194, P190, P65, P37, P43, \\
& P78 e P142 \\
G2 & P157 e P166 \\
G3 & P135 e P165 \\
G4 & P191 e P196 \\
G5 & P181 \\
G6 & P182 \\
G7 & P66 \\
G8 & P192 \\
G9 & P231 \\
G10 & P41 \\
\hline
\end{tabular}

$\mathrm{mm}$; o comprimento do estigma foi de 2,1 a 2,7 mm; o comprimento do pecíolo de 9,7 a 17,1 mm e o comprimento da placenta de 1,6 a $2 \mathrm{~mm}$.

O grupo 2 foi o único a apresentar flores com seis pétalas, o diâmetro da flor foi de 6, 2 a 6,8 mm; o comprimento do estigma de 2,8 mm; o comprimento do pecíolo de18,3 a 19,8 mm e o comprimento da antera de 2,1 a 2,2 mm.

O grupo 3 apresentou cinco pétalas; diâmetro da flor de 7,5 a $8 \mathrm{~mm}$; comprimento do estigma de 3,1 a 3,5 mm; comprimento do pecíolo de 13,9 a 17,6 mm, e, comprimento da antera de 1,9 a $2 \mathrm{~mm}$.

O grupo 4 apresentou cinco pétalas; diâmetro da flor de 9 a 10,9 mm; comprimento do estigma de 2,3 a 2,4 mm; comprimento do pecíolo de 14,5 a 20,1 mm, e, comprimento da antera de 2 e $2,1 \mathrm{~mm}$.

Os grupos de 5 a 10 apresentaram número de pétalas iguais; o comprimento da antera foi homogêneo entre os acessos, bem como o comprimento do estigma. As maiores diferenças foram observadas no diâmetro da flor e no comprimento do pecíolo. Essas diferenças podem ter contribuído na separação dos grupos, deixando estes acessos isolados.

O método de agrupamento UPGMA reuniu os acessos em quatro grupos, conforme a sua similaridade. $\mathrm{O}$ coeficiente de correlação cofenética do dendrograma ( $\mathrm{r}=$ 0,83 ) revelou um bom ajuste entre a representação gráfica das distâncias e sua matriz original (Rohlf, 2000), possibilitando a realização de inferência por meio da avaliação visual (Figura 1). Os resultados obtidos possibilitaram inferir que os acessos que mais se diferenciaram, em relação aos demais, foram o P191, P157 e P166, que formaram os grupos mais distantes, III e IV, respectivamente. Os mais similares foram P42 e P233, que estão no grupo I.

Comparando as duas formas de agrupamento, o método hierárquico UPGMA e o de Tocher, a separação dos grupos foi concordante quanto aos acessos P157 e P166, sendo parcialmente concordante para os demais. No método hierárquico UPGMA, a maior parte dos acessos foi reunida no grupo I. As diferenças encontradas entre os métodos podem ser devidas às diferentes formas de realizar os agrupamentos (Geleta et al., 2005, Votava et al., 2002).

Não foi observada relação entre os grupos formados e o local de origem geográfica dos acessos. Esses acessos são provenientes de coletas realizadas em feiras e em áreas de produção de várias regiões do Brasil: Bahia, Pará, Paraná, Rio de Janeiro, Rio Grande do Sul, Santa Catarina e Tocantins. O acesso da Guiana Francesa foi doado para o banco por colecionadores particulares de pimentas.

Baseando-se na morfologia floral, Pickersgill (1997) relatou que a caracterização morfológica de acessos tem sido utilizada, por anos, como a forma mais usual de estudar a variabilidade genética das pimentas. Este trabalho

Rev. Ceres, Viçosa, v. 59, n.4, p. 493-498, jul/ago, 2012 


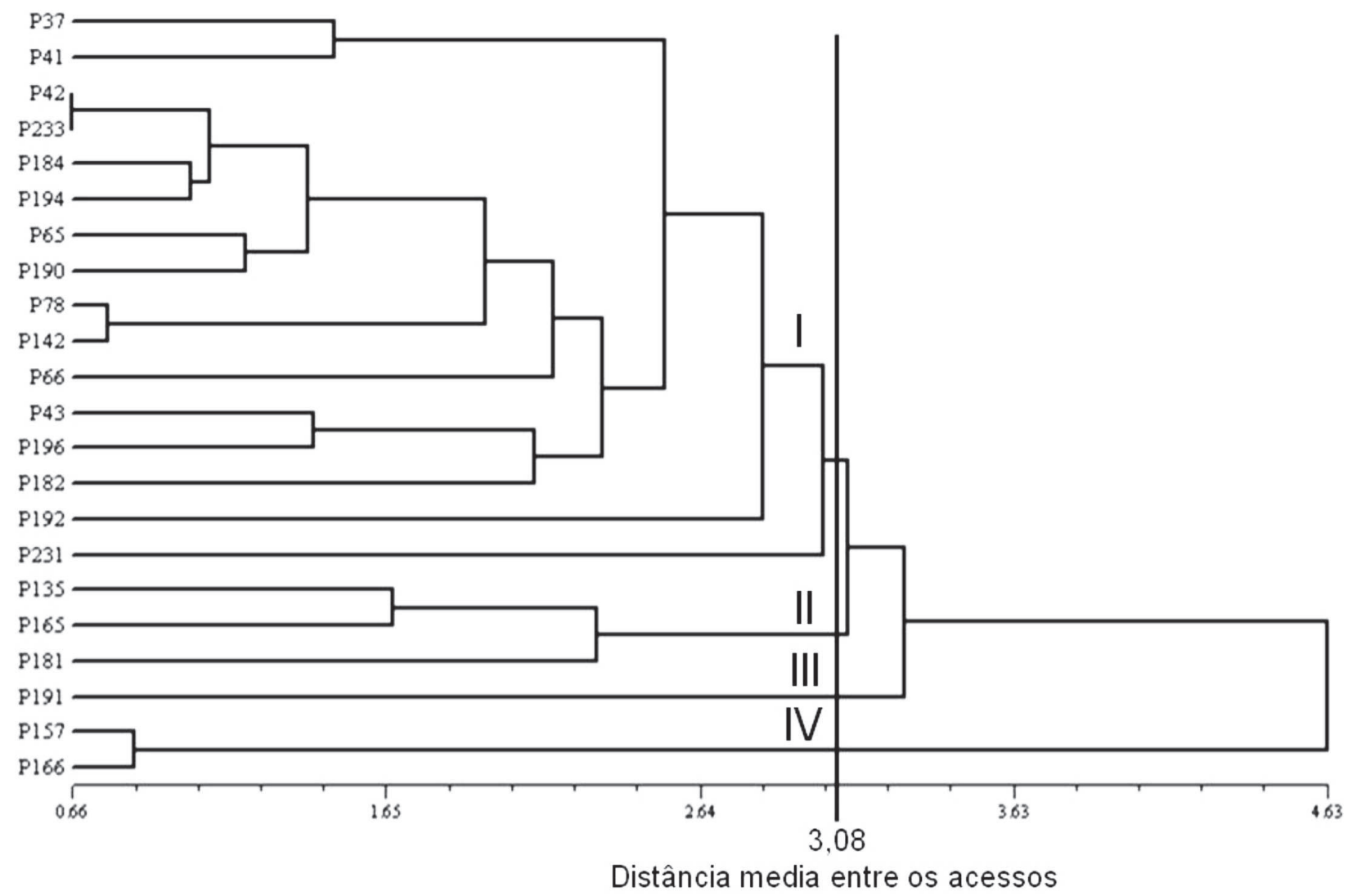

Figura 1. Dendrograma obtido a partir da análise dos dados quantitativos de 22 acessos de Capsicum chinense, por meio da distância de Mahalanobis e do método de agrupamento UPGMA. O coeficiente de correlação cofenética (r) foi de 0,83 .

demonstrou que é possível estudar a divergência genética, com base nos caracteres morfológicos de flor, e as formas de agrupamento foram eficientes, formando grupos coerentes. Esse fato também foi evidenciado pelos resultados encontrados por Neitzke et al., (2008) e Neitzke et al., (2010).

\section{CONCLUSÕES}

O uso de descritores multicategóricos de flores é eficiente para estimar a dissimilaridade genética entre acessos de Capsicum chinense.

Os acessos avaliados apresentam ampla variabilidade genética, em relação a descritores de flores.

\section{REFERÊNCIAS}

Almeida CMCV, Dias LAS, Okabe ET \& Medeiros JRP (2005) Variability in genetic resources of cacao in Rondônia, Brazil. Crop Breeding and Applied Biotechnology, 5:318-324.

Belletti P, Marzachi C \& Lanteri S (1998) Flow cytometric measurement of nuclear DNA content in Capsicum (Solanaceae). Plant Systematics and Evolution, 209:85-91.

Bento CS, Sudre CP, Rodrigues R, Riva EM \& Pereira MG (2007) Descritores qualitativos e multicategóricos na estimativa da variabilidade fenotípica entre acessos de pimentas. Scientia Agraria, 8:149-156.
Bosland PW \& Votava EJ (2000) Peppers: Vegetable and spice Capsicum. CABI Publishing, 1:199-204.

Carvalho SIC \& Bianchetti LB (2004). Botânica. Embrapa Hortaliças. Disponível em: <www.cnph.embrapa.br/sistprod/pimenta/botanica.htm>. Acessado em: 19 de julho de 2010.

Coimbra RR, Miranda GV, Moreira GR, Silva DJH, Cruz CD, Carneiro ZCS, Souza LV, Guimarães LJM, Marcasso RC \& Caniato FF (2001) Divergência genética de cultivares de milho baseada em descritores qualitativos. In: $3^{\circ}$ Simpósio de Recursos Genéticos para a America Latina e Caribe (SIRGEALC), Londrina. Anais, IAPAR. p.266-268.

Cruz CD (2006) Programa Genes: Biometria. Viçosa, Editora UFV. p. 382.

Cruz CD \& Carneiro PCS (2003) Modelos biométricos aplicados ao melhoramento genético. Viçosa, UFV. p. 585.

Cruz CD \& Regazzi AJ (1997) Modelos biométricos aplicados ao melhoramento genético. Viçosa, Editora UFV. 390p.

IPGRI, AVRDC \& CATIE (1995) Descriptores para Capsicum (Capsicum spp). International Plant Genetic Resources Institute, Rome. The Asian Vegetable Research and Development Center, Taipei. Centro Agronómico Tropical de Investigación y Enseñanza, Turrialba. 110p.

Luz FJF (2007) Caracterização morfológica e molecular de acessos de pimenta. Tese de Doutorado. Universidade Estadual Paulista, Jaboticabal. 81p.

Moreira GR, Caliman FRB, Silva DJH \& Ribeiro CSC (2006) Espécies e variedades de pimenta. Informe Agropecuário, 27:1629.

Rev. Ceres, Viçosa, v. 59, n.4, p. 493-498, jul/ago, 2012 
Neitzke RS (2008) Divergência genética entre variedades locais de Capsicum baccatum utilizando caracteres multicategóricos Revista Magistra, 20:249-255.

Neitzke RS, Barbieri RL, Rodrigues WF, Corrêa IV \& Carvalho FIF (2010) Dissimilaridade genética entre acessos de pimenta com potencial ornamental. Horticultura Brasileira, 28:47-53.

Paran I, Aftergoot E \& Shifriss C (1998) Variation in Capsicum annuum revaled by RAPD markers. Euphytica, 99:167-173.

Pickersgill B (1971) Relationships betweeen weedy and cultivated forms in some species of chilli peppers (genus Capsicum). Evolution, 25:683-691.

Pickersgill B (1993) Cytogenetics and evolution of Capsicum L. In: Tsuchiya T \& Gupta PK (Eds.) Chromosome engineering in plants: genetics, breeding, evolution. Part B. Amsterdam, Elsevier. p.139-160.

Pickersgill B (1997) Genetic resources and breeding of Capsicum ssp. Euphytica, 96:20-133.
Prince JP, Pochard E \& Tanksley SD (1993) Contruction of a molecular linkage map of peper and a comparison of synteny with tomato. Genome, 36:404-417.

Ramalho MAP, Santos JB \& Pinto CABP (2004) Genética na Agropecuária. Lavras, UFLA. 472p.

Rao RC (1952) Advanced statistical methods in biometric research. New York, John Wiley. 390p.

Rohlf FJ (2001) NTSYSpc - Numerical Taxonomy and Multivariate Analysis System. Version 2.1. New York, Exeter. Software.

Rufino JLS \& Penteado DCS (2006) Importância econômica, perspectiva e potencialidades do mercado para pimenta. Informe Agropecuário, 27:07-15.

Sokal RR \& Rohlf FJ (1962) The comparison of dendrogramas by objective methods. Taxon, 11:30-40.

Yamamoto S \& Nawata E (2005) Capsicum frutescens L. in southeast and east Asia, and its dispersal routes into Japan. Economic Botany, 59:18-28. 